\title{
ИНВАЗИВНЫЙ КЛОП NEZARA VIRIDULA L. (HEMIPTERA, РЕNTATOMIDAE) В РЕСПУБЛИКЕ МОЛДОВА
}

\author{
Иванова ${ }^{1}$ Р.А., Елисовецчкая Д.С., Бриндза ${ }^{2}$ Я. \\ ${ }^{1}$ Институт Генетики, Физиологии и Защчиты Растений, Кишинэу, Республика Молдова \\ ${ }^{2}$ Словацкий сельскохозяйственный университет, Институт сохранения \\ биоразнообразия и биологической безопасности, Нитра, Республика Словакия \\ e-mail: dina.elis.s@gmail.com \\ https://doi.org/10.53040/9789975347204.11
}

\begin{abstract}
In the summer of 2020 on the plantations of Phytolacca americana L. (pokeberry) growing in the central zone of the Republic of Moldova, a new, economically dangerous pest species was discovered, known as the southern green stink bug or southern vegetable bug - Nezara viridula L. (Heteroptera: Pentatomidae). At both stages of bug development, larvae and adults seriously harm agricultural crops, ornamental and wild plants. The number of larvae was high and reached to 3-5 per pokeberry bunch. In the same field, $N$. viridula larvae and imago were also found on tomato and amaranth plants.
\end{abstract}

Keywords: southern green stink bug, Nezara viridula, invasive pest, new record, Phytolacca americana, Solanum lycopersicum, Amaranthus retroflexus.

В настоящее время существует как минимум две версии географического происхождения зеленой незары (или зеленого овощного клопа) Nezara viridula L. (Heteroptera: Pentatomidae), что является предметом оживленных споров среди специалистов (Grozea et al., 2012). Наиболее вероятным происхождением считается Средиземноморье и/или материковая часть Африки (Hokkanen, 1986; Jones, 1988). Жизненный цикл клопа, его распространение на континентах Азии, Европы, Северной и Южной Америки, а также на островах карибского бассейна, достаточно хорошо изучены и описаны (McPherson \& McPherson, 2000; Musolin et al., 2010; McPherson, 2017). В Европе самое раннее описание вида Cimex smaragdulus F. (син. N. viridula) с острова Мадейра относится к 1775 г. (McPherson, 2017). Однако, несмотря на достаточно давнюю экспансию, несколько веков ареал вредителя в Европе ограничивался определенными территориями некоторых южных стран (юг Франции, север Италии (к югу от Альп), Словении, юг Венгрии). Дальнейшее распространение фитофага по континенту сдерживалось, в основном, климатическими условиями (Musolin et al., 2010). Ориентировочно, с 2008 года появились сообщения о расширении 
ареала N. viridula на север Европы (Rabitsch, 2008). Адаптацию клопа севернее своих раннее установившихся границ большинство авторов связывает с изменениями климата в сторону потепления и, в первую очередь, с повышением среднесуточных зимних температур, что позволяет $N$. viridula перезимовывать и успешно наращивать свою численность в новых ареалах.

Поскольку на данный момент вредитель уже достаточно широко распространен в Европе (зарегистрирован как минимум в 18 странах и на некоторых островах), а также обнаружен и у наших соседей - в Румынии (Grozea et al., 2012) и России (республика Адыгея, Краснодарский край) (Пушня и Ширинян, 2015; Pushnya, 2020), нами на протяжении ряда лет регулярно проводились обследования предполагаемых растений хозяев для выявления клопа N. viridula. Летом 2020 г. первые особи клопа были обнаружены в г. Кишиневе (р-н Ботаника), в частном секторе, на растении лаконос американский Phytolacca americana L., Phytolaccaceae (Рис. 1).

Питание личинок и имаго зеленой незары на растениях Phytolacca americana в литературе уже описано другими авторами (Vétek \& Rédei, 2014). Однако все же обнаружение его на данном растении для нас было полной неожиданностью. В первую очередь мы ожидали появление клопа на таких растениях как бобовые (соя, фасоль), крестоцветные Cruciferae, злаковые Poaceae (Gramíneae), мальвовые Malvaceae, на овощных семейства Solanaceae (томатах, перцах). Обследовали и другие культурные, а также декоративные и сорные растения, в том числе яблоню, персик, кукурузу, малину, рапс, сирень. Особое внимание уделяли регулярным обследованиям растений Hibiscus syriacus L. Данные растения в условиях центральной зоны Республики Молдова уже несколько лет как заселены другими инвазивными видами клопов: с 2015 г. его используют в качестве дополнительного хозяина клопы Oxycarenus lavaterae (Fabricius, 1787) (Heteroptera: Lygaeidae), а с прошлого, 2019 г., там встречались и личинки Halyomorpha halys Stal, 1855 (Heteroptera: Pentatomidae). Однако ни яйцекладок, ни личинок и имаго N. viridula на растениях H.syriacus в условиях Республики Молдова до сих пор нами не обнаружено. До 2020 г. вредитель также не был замечен нами ни на одном из обследованных и названных выше видов растений.

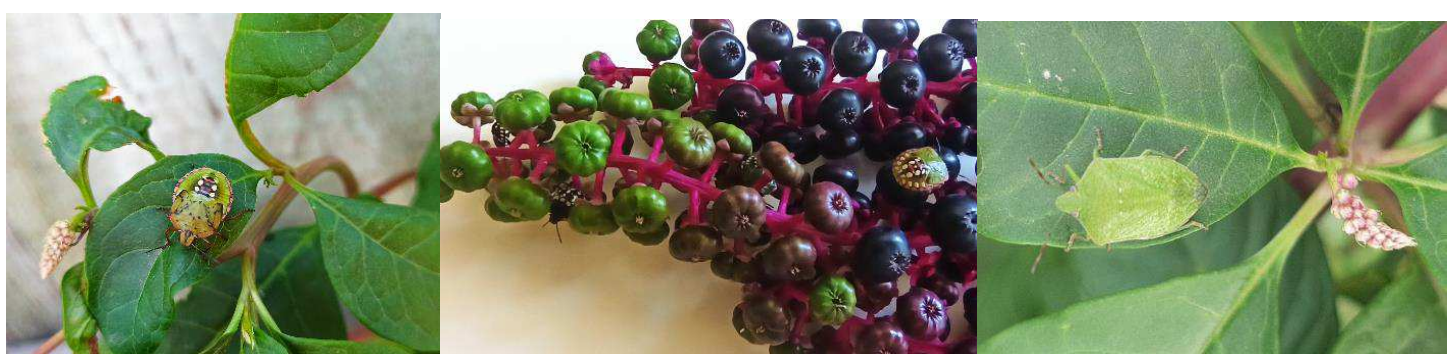

Рисунок 1. Личинки и имаго Nezara viridula L. (Heteroptera: Pentatomidae) на Phytolacca americana L. (Phytolaccaceae)

Не исключено, что инвазия фитофага произошла совсем недавно, скорее всего именно в текущем 2020 году, поэтому плотность существующих популяций пока невысокая, и фитофаг рассредоточен на различных сорных, древесных и других растениях, а проведение в хозяйствах регулярных химических обработок на культурных растениях сдерживает численность клопов и затрудняет их обнаружение. По этим причинам, скорее всего, вредитель и был выявлен впервые в частном секторе (координаты: 4699' северной широты, 2886' восточной долготы), где выращивается 
достаточно широкий ассортимент растений и полностью отсутствуют обработки синтетическими пестицидами. Были обнаружены имаго и личинки N. viridula всех возрастов, питающиеся зелеными и созревающими ягодами лаконоса американского (Рис. 1). Численность личинок на растениях варьировала от 1-2 на кисть, при единичном заселении растения, до 5-10 на кисть при заселении около 30\% кистей.

Достоверно неизвестно, какие из видов растений были заселены клопом N. viridula на участке в первую очередь. Однако на растении Phytolacca americana личинки были замечены нами случайно, и после этого уже было проведено обследование и других культур. В результате выявлена высокая численность личинок и имаго клопа также на томатах Solanum lycopersicum L. (Solanaceae) и на амаранте запрокинутом Amaranthus retroflexus L. (Amaranthaceae) (Рис. 2). Плоды томатов имели все признаки повреждения сосущими насекомыми и многие из них потеряли свой товарный вид, а также некоторые имели признаки поражения плесневыми грибами и опали с куста недозревшими. Хорошо известно, что урон растениям наносят как личинки, так и имаго вредителя (Grozea et al., 2012). Клопы повреждают листовые и цветочные почки, побеги, плоды, а у бобовых - молодые, еще не затвердевшие бобы и семена. В результате потери урожая могут достигать колоссальных размеров, также происходит порча товарного вида и поражение растений патогенами из-за наносимых клопом повреждений.
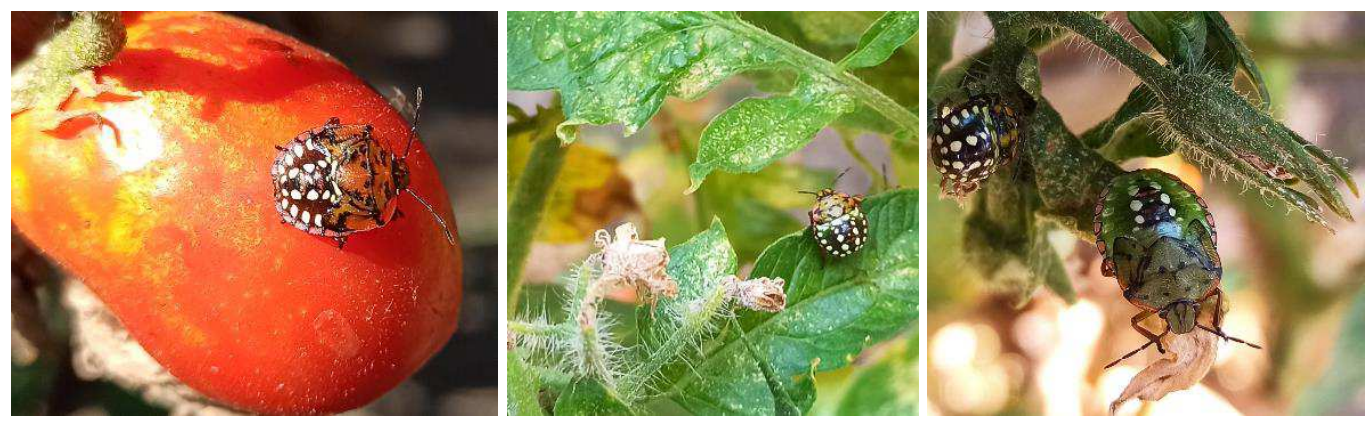

Рисунок 2. Nezara viridula L. на Solanum lycopersicum L., Solanaceae

Ранее, в период с 2017 по 2019 гг., нами проводился ежегодный мониторинг и наблюдения за пищевыми предпочтениями инвазивного клопа-щитника N. viridula в некоторых областях Словакии. Впервые в Словакии клопа обнаружили в г. Штурово на границе с Венгрией (Vétek \& Rédei, 2014). В дальнейшем было подтверждено, что вид акклиматизировался и закрепился на новой территории (Hemala \& Kment, 2017). Нами регистрировались имаго и личинки N. viridula как на границе с Венгрией в г. Штурово, так и в г. Нитра (на расстоянии 90 км от г. Штурово) и его окрестностях на самых разных культурах - от сорных растений до кустарников и деревьев, а также на некоторых культурных растениях (Рис. 4, 5). В 2018-2019 г. численность популяции $N$. viridula в парках, садах, на приусадебных участках и в хозяйствах Республики Словакия существенно возросла. Клопа регистрировали на Pyracantha M.Roem. Rosaceae валериане лекарственной Valeriana officinalis L., Caprifoliáceae, амаранте запрокинутом Amaranthus retroflexus L., Amarantháceae, пасленовых (томат, перцы) и некоторых других растениях (Рис. 5). 


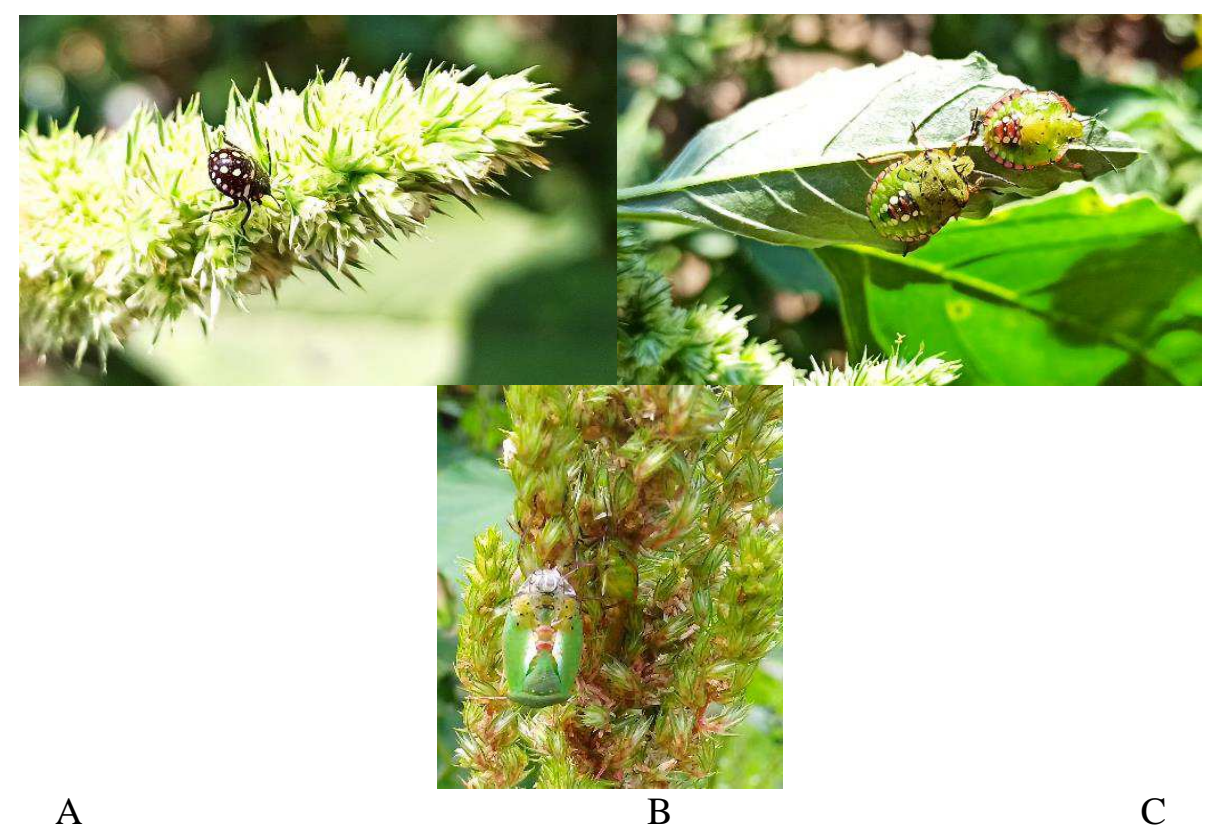

Рисунок 3. Nezara viridula L. на Amaranthus retroflexus L., Amarantháceae: A-личинка третьего возраста, В -личинки старших возрастов, $\mathrm{C}$ - линька в имаго

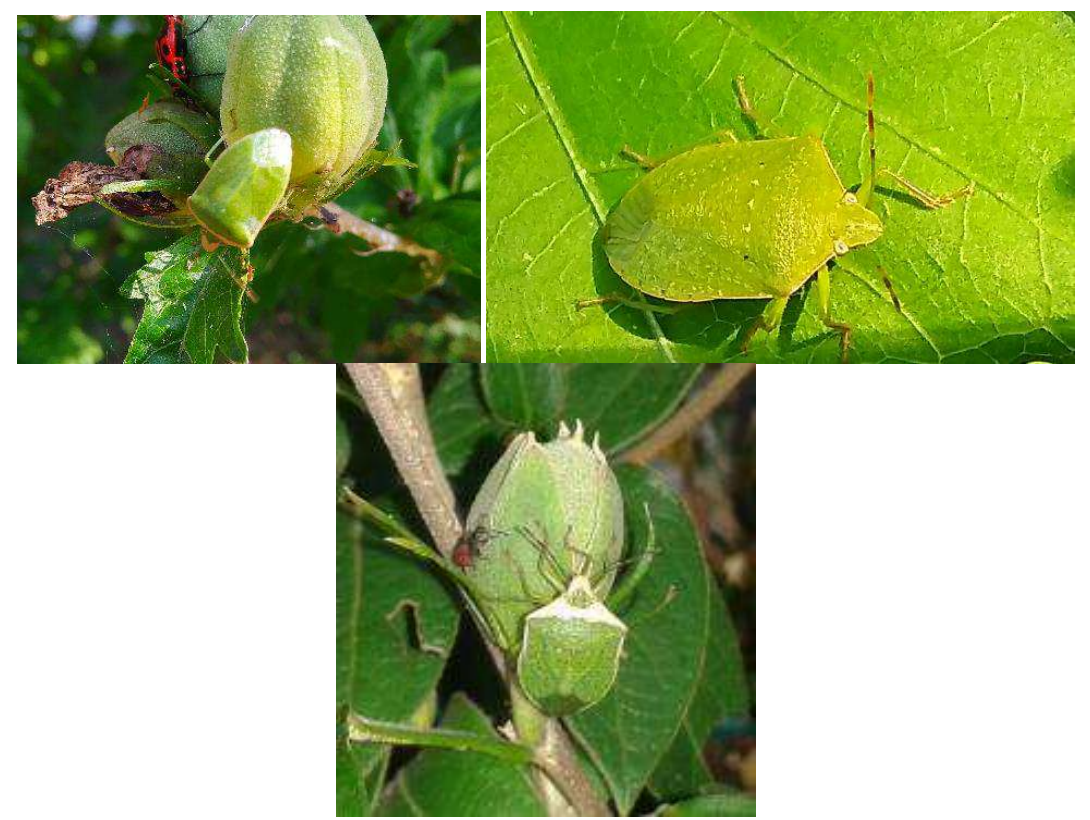

Рисунок 4. Nezara viridula L.: имаго, различные морфы, Нитра, Словакия, 2017-2019 


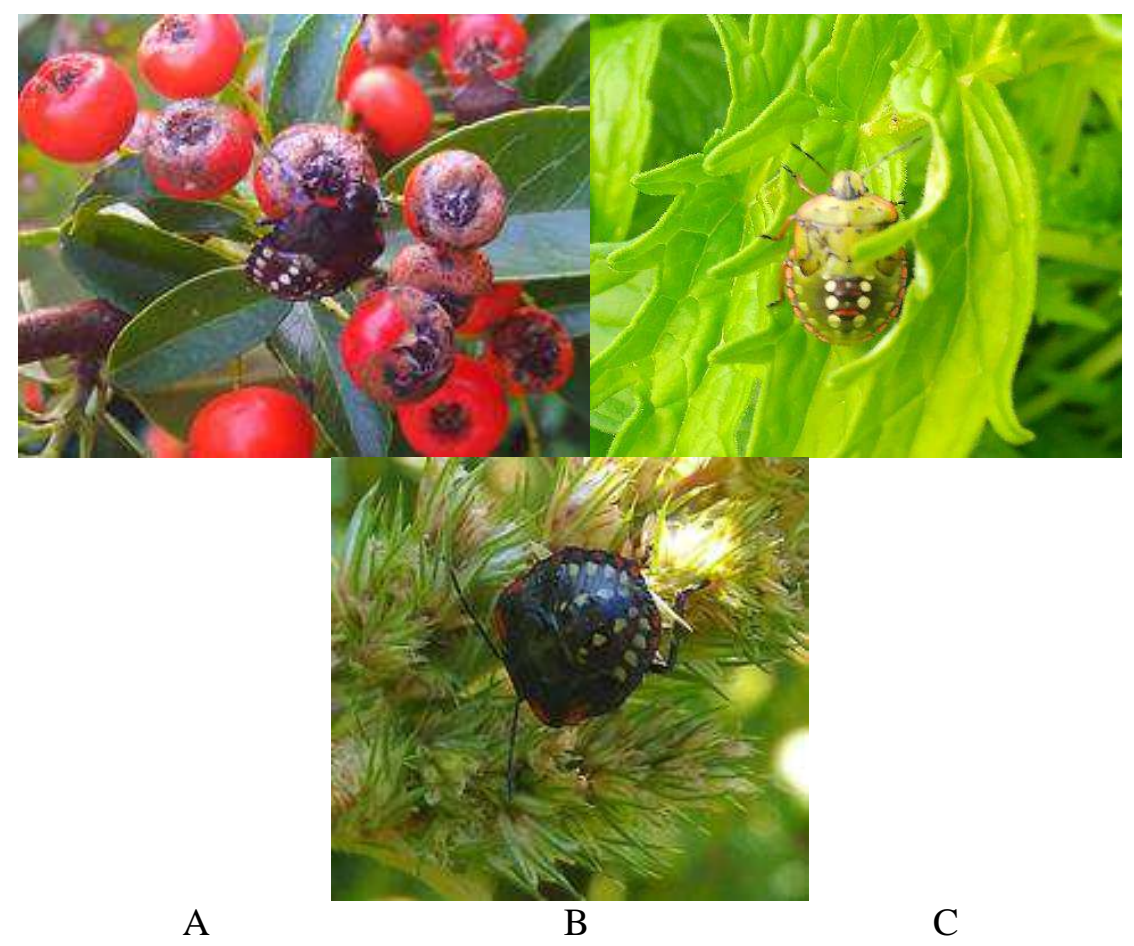

Рисунок 5. Личинки Nezara viridula L. на различных видах растений: A - Pyracantha M.Roem., Rosaceae, B - Valeriana officinalis L., Caprifoliáceae, C - Amaranthus retroflexus L., Amarantháceae, Нитра, Словакия, 2017-2019

Таким образом, обнаружен новый для Республики Молдова инвазивный вид Nezara viridula L. (Heteroptera: Pentatomidae) на растениях Phytolacca americana L. (Phytolaccaceae), которые также являются интродуцентами для республики. Акклиматизация опасного полифага представляет серьезную угрозу для многих сельскохозяйственных культур, в том числе для злаковых, бобовых, пасленовых, кукурузы и многих других видов. Вредитель может причинять значительный ущерб также декоративным и лесным насаждениям. Пример адаптации и значительного увеличения плотности популяций всего за несколько лет после первых случаев обнаружения в условиях Словакии говорит о высоком потенциале фитофага. Поэтому необходимо обратить пристальное внимание на вопросы мониторинга и разработку превентивных и защитных мероприятий для снижения численности экономически значимого вредителя.

Благодарность: Авторы искренне благодарят Международный Вышеградский фонд (Visegrad Fund) в Братиславе за поддержку исследований посредством предоставления стипендиального гранта №51910230 и финансирования билатерального проекта (Республика Словакия - Республика Молдова) 2019-2020гг.

\section{Библиография}

Grozea I., Ştef R., Virteiu A. M., Cărăbeţ A., Molnar L. 2012 Southern green stink bugs (Nezara viridula L.) a new pest of tomato crops in Western Romania. Research Journal of Agricultural Science, vol. 44 (2), p. 24-27 
Hemala V., Kment P. 2017. First Record of Halyomorpha halys and mass occurrence of Nezara viridula in Slovakia. Plant Protect. Sci., vol. 53, no. 4: 247-253. doi: 10.17221/166/2016-PPS

Hokkanen H. 1986. Polymorphism, parasites, and the native area of Nezara viridula (Hemiptera, Pentatomidae). Annales Entomologici Fennici, vol. 52(1), p. 28-31

Jones W.A., 1988. World review of the parasitoids of the southern green stink bug, Nezara viridula (L.) (Heteroptera: Pentatomidae). Annals of the Entomological Society of America, vol. 81(2), p. 262-273

McPherson, J. E. 2017. Invasive stink bugs and related species (Pentatomoidea): biology, higher systematics, semiochemistry, and management. Boca Raton: Taylor \& Francis Group, LLC. 820 p. ISBN 9781498715089

McPherson, J. E., McPherson, R. M. 2000. Stink bugs of economic importance in America north of Mexico. CRC Press, Boca Raton, FL. 253 pp.

Musolin D.L, Tougou D., Fujisaki K. 2010. Too hot to handle? Phenological and life-history responses to simulated climate change of the southern green stink bug Nezara viridula (Heteroptera: Pentatomidae). Glob. Change Biology, vol. 16, p. 73-87. http://doi.org/10.1111/j.1365- 2486.2009.01914.x 3.

Pushnya M., Rodionova E., Snesareva E. 2020. Development of the elements of the biological system for protecting crops against the southern green stink bug Nezara viridula L. (Hemiptera: Pentatomidae) in Krasnodar Krai. XI Intern.Sc. and Practical Conference "Biological Plant Protection is the Basis of Agroecosystems Stabilization", BIO Web of Conferences, vol. 21, article no. 00037, 5 p. https://doi.org/10.1051/bioconf/20202100037

Rabitsch W. 2008. Alien true bugs of Europe (Insecta: Hemiptera: Heteroptera). Zootaxa, vol. 1827, p. 1-44.

Vétek G., Rédei D. 2014. First record of the southern green stink bug, Nezara viridula, from Slovakia (Hemiptera: Heteroptera: Pentatomidae). Klapalekiana, vol. 50, p. 241-245. ISSN 12106100

Пушня, М.В., Ширинян Ж.А. 2015. Новый опасный вредитель сои в Краснодарском крае. Защита растений и карантин, №10, с. 27-29. 